\title{
Having a Personal Healthcare Provider and Receipt of Adequate Cervical and Breast Cancer Screening
}

\author{
Roberto Cardarelli, DO, MPH, Anita K. Kurian, DrPH, MBBS, and \\ Vishwam Pandya, MD, MPH
}

Introduction: The purpose of this study was to assess the relationship between having a personal health care provider and adequate cervical and breast cancer screening behavior.

Methods: Cross-sectional data were obtained from the 2004 Behavior Risk Factor Surveillance System. For cervical cancer, female respondents 18 years of age and older who did not have hysterectomy were included $(n=130,359)$; for breast cancer, female respondents 40 years of age or older were included $(\mathrm{n}=129,929)$. Multiple logistic regression analyses were performed to determine the association between having a personal health care provider, specific demographics, and health insurance status with adequate cervical and breast cancer screening behavior.

Results: Approximately $9 \%$ and $14 \%$ of the study population for the breast cancer and cervical cancer analyses, respectively, did not have a personal health care provider. Having at least one personal health care provider was significantly associated with adequate cervical cancer screening behavior (odds ratio, 2.37; 95\% CI, 2.08-2.70) and breast cancer screening behavior (odds ratio, 2.86; 95\% CI, 2.54-3.24) in multivariate analyses. Both multivariate analyses were adjusted for age, race/ethnicity, education, income, and health insurance.

Conclusion: Having at least one personal health care provider was associated with adequate cervical and breast cancer screening behavior. Efforts to increase primary care access are a necessary part of the plan to increase preventive health services utilization. (J Am Board Fam Med 2010;23:75-81.)

Despite spending $\$ 2$ trillion per year (16\% of gross domestic product) on health care, the US health care system faces challenges related to uninsured people (approximately 45 million), access to care, high cost, and racial/ethnic health care inequities. ${ }^{1}$ The US ranks lowest in patient satisfaction and

This article was externally peer reviewed.

Submitted 23 February 2009; revised 4 May 2009; accepted 7 May 2009.

From the Primary Care Research Institute, University of North Texas Health Science Center at Fort Worth and the Department of Family Medicine, Texas College of Osteopathic Medicine (RC, VP); and Tarrant County Public Health (AKK), Fort Worth, TX.

Funding: This manuscript was supported in part by the National Institutes of Health/ National Center on Minority Health and Health Disparities grant no. 1-P20-MD001633010003.

Conflict of interest: none declared.

Corresponding author: Roberto Cardarelli, DO, MPH, Acting Chairman of Family Medicine and Director, Primary Care Research Institute, UNT Health Science Center, 3500 Camp Bowie Blvd., Fort Worth, TX 76107 (E-mail: rcardare@hsc.unt.edu).

\footnotetext{
See Related Commentary on Page 6.
}

health indicators among developed countries, highlighting a need for health care reform. ${ }^{2}$ Reports from other countries have shown that primary care physicians are one of the most important resources for providing high-quality health care. ${ }^{1}$ The Institutes of Medicine promulgates the importance of primary care in disease prevention, health promotion, and early detection of illnesses, ${ }^{3}$ which is evidenced by numerous studies. ${ }^{4}$ Primary care's impact has been especially highlighted in relation to preventive services utilization and cancer screening. However, it remains unclear whether health insurance status and having a primary care physician are independently related or interrelated to adequate cancer screening. ${ }^{5-7}$

Cervical and breast cancers cause a significant health burden among women, representing 34\% of newly diagnosed cancers and $16 \%$ of all cancer deaths in United States. ${ }^{5}$ Although screening rates for cervical and breast cancer have been increasing, they are still far from optimal. ${ }^{5}$ Moreover, the 2003 National Health Care Disparities Report and the recent Surveillance Epidemiology and End Results Cancer Statistics Review found that minorities are less likely to receive cancer screening and have 
higher death rates. ${ }^{8,9}$ One predictor of adequate cervical cancer screening has been access to primary care physicians. ${ }^{10,11}$

The purpose of this study was to assess the association between having a personal health care provider (PHP) and adequate cervical and breast cancer screening after controlling for age, race/ ethnicity, education, income, and health insurance status using data from the 2004 national Behavioral Risk Factor Surveillance System (BRFSS).

\section{Materials and Methods}

The BRFSS is a state-based surveillance system conducted by the Centers for Disease Control and Prevention. Trained interviewers collected self-reported data from a random sample of civilian, noninstitutionalized adults (one per household) through a telephone interview. The questionnaire included (1) a core component; (2) optional modules; and (3) questions added by the state. The core component was a standard set of 119 questions asked by all states; the optional modules were questions on specific topics that states elected to include as part of their questionnaires. The 2004 median response rate was $52.7 \%$.

\section{Inclusion Criteria}

The study included female respondents from all 50 states. In addition, for cervical cancer, respondents were included if they were 18 years of age or older and did not have a hysterectomy. Similarly, for breast cancer, respondents were included if they were 40 years of age or older. The 2003 US Preventive Task Force recommendations were followed for this study because 2004 BRFSS data were used.

\section{Dependent Variables}

The outcome of interest was responses to the women's health section of the 2004 BRFSS. For cervical cancer, respondents were considered to be adequately screened if they had a Papanicolaou test within the previous 3 years. For breast cancer, respondents were considered to be adequately screened if they had a mammogram within the previous 2 years. The response was dichotomized as either "adequately screened" or "not adequately screened." Although Papanicolaou tests are only used for screening purposes, mammograms can be used for both screening and diagnostic purposes.
Although BRFSS questions did not ask about the purpose of the mammogram, the authors are using the term "screening" for both cervical and breast cancer testing.

\section{Independent Variable}

The primary independent variable was based on the question, Do you have one person you think of as your personal doctor or health care provider? Responses included "yes, only one," "more than one," or "no." It should be noted that the BRFSS did not allow differentiation between a non-primary care clinician, primary care physician, or a primary care mid-level provider; hence, "personal health care provider" is the preferred term in this article. The term "personal health care provider" is conceptualized as a proxy measure for a primary care clinician in the current study, especially for responses that included "yes, only one" because this reflects a more traditional primary care relationship. After missing data for PHP were taken into account, there were 130,359 and 129,929 individuals remaining in cervical cancer screening and breast cancer screening analyses, respectively.

\section{Covariates}

The covariates included (1) age; (2) race/ethnicity (non-Hispanic white, non-Hispanic African American, non-Hispanic other, non-Hispanic multiracial, or Hispanic); (3) education level (not a high school graduate, high school graduate or greater); (4) annual household income level $(<\$ 25 \mathrm{k}$, $\geq \$ 25 \mathrm{k}$ ); and (5) having health insurance (yes or no).

\section{Analysis}

Descriptive statistics were calculated for the participants using weighted population percentages. Categorical and continuous data were analyzed using $\chi^{2}$ and analyses of variance statistical tests, respectively, to determine the differences in the study population characteristics between the 3 subgroups of patients having a PHP. Univariate logistic regression analyses were conducted to determine the association between the dependent and independent variables. Multiple logistic regression analysis was conducted to control for confounding variables. Covariates that were significantly associated with adequate cervical and breast cancer screening or known as independent predictors in previous studies were included in the multiple logistic re- 


\begin{tabular}{|c|c|c|c|c|c|}
\hline Variables & $\begin{array}{c}\text { One PHP } \\
(\mathrm{n}=100,031) \\
(\%)^{\dagger}\end{array}$ & $\begin{array}{c}\text { More Than } \\
\text { One PHP } \\
(\mathrm{n}=11,601) \\
(\%)\end{array}$ & $\begin{array}{c}\text { No PHP } \\
(\mathrm{n}=18,727) \\
(\%)\end{array}$ & $\begin{array}{c}\text { Total } \\
(\mathrm{n}=130,359) \\
(\%)\end{array}$ & $P$ \\
\hline Age, mean years (SD) & $51.7(16.8)$ & $53.2(17.7)$ & $41.6(15.6)$ & $50.2(17.1)$ & $<.001$ \\
\hline Race/ethnicity & & & & & $<.001$ \\
\hline Non-Hispanic white & 72.8 & 69 & 51.7 & 68.8 & \\
\hline Non-Hispanic African American & 10.5 & 9.5 & 11.2 & 10.5 & \\
\hline Non-Hispanic other & 3.9 & 4.9 & 4.6 & 4.1 & \\
\hline Non-Hispanic multiracial & 1.3 & 1.8 & 1.4 & 1.4 & \\
\hline Hispanic & 11.5 & 14.7 & 31.1 & 15.2 & \\
\hline Education level & & & & & $<.001$ \\
\hline Did not graduate high school & 9.2 & 10.5 & 20.5 & 11.2 & \\
\hline High school graduate or greater & 90.8 & 89.5 & 79.5 & 88.8 & \\
\hline Income & & & & & $<.001$ \\
\hline$<\$ 25,000$ & 27.4 & 30.3 & 52.1 & 31.8 & \\
\hline$\geq \$ 25,000$ & 72.6 & 69.7 & 47.9 & 68.2 & \\
\hline Health insurance & & & & & $<.001$ \\
\hline Yes & 90.7 & 89.6 & 53.3 & 84.1 & \\
\hline No & 9.3 & 10.4 & 46.7 & 15.9 & \\
\hline Adequate cervical cancer screening ${ }^{\ddagger}$ & & & & & $<.001$ \\
\hline Yes & 86.6 & 87.4 & 73.7 & 84.5 & \\
\hline No & 13.4 & 12.6 & 26.3 & 15.5 & \\
\hline
\end{tabular}

*According to the 2004 United States Behavior Risk Factor Surveillance System.

${ }^{\dagger}$ Weighted percent.

${ }^{\ddagger}$ Adequate cervical cancer screening defined as Pap smear within the previous 3 years.

PHP, personal health care provider.

gression model. Statistical significance was established as $P<.05$. The final sample size used in the multiple logistic regression analysis included 111,600 and 106,288 individuals for cervical cancer and breast cancer analysis, respectively, after the patients who had missing data values were excluded from the analyses. All analyses were conducted using SPSS software (version 14.0; SPSS, Inc., Chicago, IL); the Complex Sample Module used the stratum, primary sampling units, and weights to take account of the complex sample design. Details of how weighting was calculated have been described in detail elsewhere. ${ }^{12}$

\section{Results}

The study sample characteristics by cervical cancer and breast cancer screening behavior are shown in Tables 1 and 2, respectively. A total of 130,359 respondents were included in the cervical cancer screening behavior analyses, of which $14.3 \%(\mathrm{n}=$ 18,727) reported having no PHP. Similarly, for breast cancer screening behavior analyses, a total of 129,929 respondents were included, of which $9.1 \%$
( $\mathrm{n}=11,835)$ reported having no PHP. Patients reporting no PHP tended to be younger, had lower levels of education and income, had no health insurance, and were less likely to receive adequate cervical and breast cancer screening compared with those with at least one PHP. A greater proportion of Hispanics reported having no PHP in both analyses.

\section{Cervical Cancer}

The results of the univariate and multivariate logistic regression analyses are shown in Table 3. The univariate analyses showed those with one or more than one PHP to be significantly more likely to have adequate cervical cancer screening compared with those with no PHP (one PHP: odds ratio [OR], 2.31; 95\% CI, 2.09-2.55; more than one PHP: OR, 2.46; 95\% CI, 2.08-2.92). NonHispanic other and Hispanics were $45 \%$ and $20 \%$ less likely to have adequate cervical cancer screening, respectively, compared with non-Hispanic whites. Those who did not graduate from high school (OR, 0.52; 95\% CI, 0.46-0.58) and who had 


\begin{tabular}{|c|c|c|c|c|c|}
\hline Variables & $\begin{array}{c}\text { One PHP } \\
(\mathrm{n}=105,250) \\
(\%)^{\dagger}\end{array}$ & $\begin{array}{c}\text { More Than } \\
\text { One PHP } \\
(\mathrm{n}=12,844) \\
(\%)\end{array}$ & $\begin{array}{c}\text { No PHP } \\
(\mathrm{n}=11,835) \\
(\%)\end{array}$ & $\begin{array}{c}\text { Total } \\
(\mathrm{N}=129,929) \\
(\%)\end{array}$ & $P$ \\
\hline Age, mean years (SD) & $59.5(13.0)$ & $60.5(13.3)$ & $54.9(12.0)$ & $59.2(13.0)$ & $<.001$ \\
\hline Race/ethnicity & & & & & $<.001$ \\
\hline Non-Hispanic white & 77.5 & 74.1 & 59.8 & 75.5 & \\
\hline Non-Hispanic African American & 9.4 & 9.2 & 10.6 & 9.5 & \\
\hline Non-Hispanic other & 3 & 3.5 & 3.9 & 3.2 & \\
\hline Non-Hispanic multiracial & 1.1 & 1.8 & 1.4 & 1.2 & \\
\hline Hispanic & 8.9 & 11.4 & 24.3 & 10.6 & \\
\hline Education level & & & & & $<.001$ \\
\hline Did not graduate high school & 11.6 & 13.7 & 22.7 & 12.9 & \\
\hline High school graduate or greater & 88.4 & 86.3 & 77.3 & 87.1 & \\
\hline Income & & & & & $<.001$ \\
\hline$<\$ 25,000$ & 31.3 & 34.9 & 51.2 & 33.5 & \\
\hline$\geq \$ 25,000$ & 68.7 & 65.1 & 48.8 & 66.5 & \\
\hline Health insurance & & & & & $<.001$ \\
\hline Yes & 93.1 & 93.2 & 60.4 & 90 & \\
\hline No & 6.9 & 6.8 & 39.6 & 10 & \\
\hline Adequate breast cancer screening ${ }^{\ddagger}$ & & & & & $<.001$ \\
\hline Yes & 77 & 77.4 & 45.4 & 74.1 & \\
\hline No & 23 & 22.6 & 54.6 & 25.9 & \\
\hline
\end{tabular}

*According to the 2004 United States Behavior Risk Factor Surveillance System.

${ }^{\dagger}$ Weighted percentage.

${ }^{\ddagger}$ Adequate breast cancer screening defined as mammogram within the previous 2 years.

$\mathrm{PHP}$, primary health care provider.

an annual income $<\$ 25,000$ (OR, 0.38; 95\% CI, $0.35-0.42)$ were also significantly less likely to be associated with adequate cervical cancer screening. Those with health insurance were approximately 2 times more likely to have adequate cervical cancer screening. Interestingly, non-Hispanic African Americans were $20 \%$ more likely to have adequate cervical cancer screening compared with non-Hispanic whites. Non-Hispanic multiracial was the only variable not associated with adequate cervical cancer screening.

After taking age, race/ethnicity, education, income, and health insurance status into account, having a personal health care provider remained the most significant predictor of adequate cervical cancer screening in the multivariate analyses. Those with one or more than one PHP were significantly more likely to have adequate cervical cancer screening (one PHP: OR, 2.37; 95\% CI, 2.082.70; more than one PHP: OR, 2.66; 95\% CI, 2.13-3.32). Although other covariates remained or became significant predictors, having a PHP had the highest odds of predicting adequate cervical cancer screening. One noteworthy change in the multivariate analyses was that Hispanics were 25\% more likely to have adequate cervical cancer screening compared with non-Hispanic whites. In addition, not graduating from high school became nonsignificant in the multivariate analyses (OR, $0.91 ; 95 \%$ CI, 0.77-1.07).

\section{Breast Cancer}

The results of the univariate and multivariate logistic regression analyses are shown in Table 4. The univariate analyses showed those with one or more than one PHP to be significantly more likely to have adequate breast cancer screening compared with those with no PHP (one PHP: OR, 4.03; 95\% CI, 3.63-4.49; more than one PHP: OR, 4.11; $95 \%$ CI, 3.56-4.76). Moreover, non-Hispanic other, non-Hispanic multiracial, and Hispanics were $32 \%, 30 \%$, and $19 \%$ less likely to have adequate breast cancer screening, respectively, compared with non-Hispanic whites. Not graduating high school (OR, 0.60; 95\% CI, 0.54-0.66) and having annual income $<\$ 25,000$ (OR, 0.55; 95\% CI, 0.51- 
Table 3. Logistic Regression Analyses of Predictors of Adequate Cervical Cancer Screening*

\begin{tabular}{|c|c|c|}
\hline Variables & $\begin{array}{c}\text { Unadjusted } \\
(\mathrm{n}=130,359)\end{array}$ & $\begin{array}{c}\text { Adjusted } \\
(\mathrm{n}=111,600)^{\dagger}\end{array}$ \\
\hline \multicolumn{3}{|l|}{$\begin{array}{l}\text { Personal healthcare } \\
\text { provider }\end{array}$} \\
\hline None & RG & RG \\
\hline One & $2.31(2.09-2.55)$ & $2.37(2.08-2.70)$ \\
\hline More than one & $2.46(2.08-2.92)$ & $2.66(2.13-3.32)$ \\
\hline Age & $0.98(0.98-0.99)$ & $0.98(0.97-0.98)$ \\
\hline \multicolumn{3}{|l|}{ Race/ethnicity } \\
\hline Non-Hispanic white & RG & RG \\
\hline $\begin{array}{l}\text { Non-Hispanic African } \\
\text { American }\end{array}$ & $1.20(1.04-1.39)$ & $1.48(1.24-1.75)$ \\
\hline Non-Hispanic other & $0.55(0.45-0.68)$ & $0.52(0.40-0.67)$ \\
\hline $\begin{array}{l}\text { Non-Hispanic } \\
\text { multiracial }\end{array}$ & $0.81(0.58-1.14)$ & $0.64(0.43-0.94)$ \\
\hline Hispanic & $0.80(0.69-0.92)$ & $1.25(1.04-1.51)$ \\
\hline \multicolumn{3}{|l|}{ Education level } \\
\hline High school or greater & RG & RG \\
\hline $\begin{array}{l}\text { Did not graduate high } \\
\text { school }\end{array}$ & $0.52(0.46-0.58)$ & $0.91(0.77-1.07)$ \\
\hline \multicolumn{3}{|l|}{ Income } \\
\hline$\geq \$ 25,000$ & RG & RG \\
\hline$<\$ 25,000$ & $0.38(0.35-0.42)$ & $0.47(0.42-.52)$ \\
\hline \multicolumn{3}{|l|}{ Health insurance } \\
\hline No & RG & RG \\
\hline Yes & $1.96(1.77-2.17)$ & $1.45(1.26-1.67)$ \\
\hline
\end{tabular}

Data provided as odds ratio (95\% CI).

*Adequate cervical cancer screening defined as Pap test within the previous 3 years. Data according to the 2004 United States Behavioral Risk Factor Surveillance System.

${ }^{\dagger}$ Based on missing data for the entire adjusted model. RG, referent group.

0.59) were also significantly associated with adequate breast cancer screening. Those with health insurance were more than 3 times more likely to have adequate breast cancer screening. Non-Hispanic African American was the only variable not associated with adequate breast cancer screening.

After taking age, race/ethnicity, education, income, and health insurance status into account, having a PHP remained the most significant predictor of adequate breast cancer screening in the multivariate analyses. Those with one or more than one PHP were significantly more likely to have adequate breast cancer screening (one PHP: OR, 2.86; 95\% CI, 2.54-3.24; more than one PHP: OR, 2.96; 95\% CI, 2.51-3.48). Although other covariates remained or became significant predictors, having a PHP had the highest odds of predicting adequate breast cancer screening. Among noteworthy changes in the multivariate analyses, non-His- panic African Americans and Hispanics were 36\% and $60 \%$ more likely to have adequate breast cancer screening compared with non-Hispanic whites, respectively.

\section{Discussion}

Multiple issues impact the receipt of adequate cervical and breast cancer screening. These include patient-level factors; provider-level factors (eg, gender of the provider, provider awareness) $)^{13,14}$; socioeconomic factors (eg, education and income); and system-level factors (eg, health insurance, PHP). ${ }^{15}$ However, the literature about the impact of the 2 system-level factors (health insurance and PHP) on cervical and breast cancer screening behavior has yielded conflicting results. Nash et $\mathrm{al}^{5}$ reported that PHP and health insurance had independent effects on cancer screening behavior and

Table 4. Logistic Regression Analyses of Predictors of Adequate Breast Cancer Screening*

\begin{tabular}{|c|c|c|}
\hline Variables & $\begin{array}{c}\text { Unadjusted } \\
(\mathrm{n}=129,929)\end{array}$ & $\begin{array}{c}\text { Adjusted } \\
(\mathrm{n}=106,288)^{\dagger}\end{array}$ \\
\hline \multicolumn{3}{|l|}{$\begin{array}{l}\text { Personal healthcare } \\
\text { provider }\end{array}$} \\
\hline None & RG & RG \\
\hline One & $4.03(3.63-4.49)$ & $2.86(2.54-3.24)$ \\
\hline More than one & $4.11(3.56-4.76)$ & $2.96(2.51-3.48)$ \\
\hline Age & $1.01(1.00-1.01)$ & $1.01(1.01-1.02)$ \\
\hline \multicolumn{3}{|l|}{ Race/ethnicity } \\
\hline Non-Hispanic white & RG & RG \\
\hline $\begin{array}{l}\text { Non-Hispanic African } \\
\text { American }\end{array}$ & $1.00(0.90-1.12)$ & $1.36(1.20-1.55)$ \\
\hline Non-Hispanic other & $0.68(0.54-0.84)$ & $0.84(0.65-1.08)$ \\
\hline $\begin{array}{l}\text { Non-Hispanic } \\
\text { multiracial }\end{array}$ & $0.70(0.53-0.93)$ & $0.82(0.60-1.12)$ \\
\hline Hispanic & $0.81(0.71-0.93)$ & $1.60(1.34-1.90)$ \\
\hline \multicolumn{3}{|l|}{ Education level } \\
\hline High school or greater & RG & RG \\
\hline $\begin{array}{l}\text { Did not graduate high } \\
\text { school }\end{array}$ & $0.60(0.54-0.66)$ & $0.78(0.69-0.89)$ \\
\hline \multicolumn{3}{|l|}{ Income } \\
\hline$\geq \$ 25,000$ & RG & RG \\
\hline$<\$ 25,000$ & $0.55(0.51-0.59)$ & $0.57(0.52-0.62)$ \\
\hline \multicolumn{3}{|l|}{ Health insurance } \\
\hline No & RG & RG \\
\hline Yes & $3.38(3.06-3.74)$ & $2.03(1.80-2.29)$ \\
\hline
\end{tabular}

Data provided as odds ratio $(95 \% \mathrm{CI})$.

*Adequate breast cancer screening defined as mammogram within the previous 2 years. Data is according to the 2004 United States Behavioral Risk Factor Surveillance System. ${ }^{\dagger}$ Based on missing data for the entire adjusted model RG, referent group. 
that these 2 system-level factors were the most important predictors of adequate cervical and breast cancer screening. A Women's Health Initiative study involving data from approximately 55,000 women concluded that, after controlling for socioeconomic characteristics, chronic medical conditions, perceived health, and having regular source of health care, health insurance remained a potent predictor of cancer screening. ${ }^{6}$ On the other hand, Coughlin et $\mathrm{al}^{7}$ suggested that the effects of PHP supply on cervical and breast cancer screening were not modified by health insurance status.

In the light of these conflicting studies, this study tried to assess the effects of the aforementioned 2 system-level factors on cancer screening behavior. In accordance with the existing literature, education, income, having health insurance, and having a PHP were found to be significant predictors of adequate cervical cancer screening behavior $^{11,15-17}$; age, education, income, having health insurance, and having a PHP were found to be significant predictors of adequate breast cancer screening behavior. ${ }^{11,18,19}$ Overall, our findings from analyses of the 2004 national BRFSS sample provide strong evidence to support that having a PHP and health insurance are 2 important independent factors associated with adequate cervical and breast cancer screening.

There were several limitations to this study that must be acknowledged. As with any self-reported survey, the data were subject to recall and related differential misclassification biases. There is a possibility for incorrect interpretation of questions, variations in interview techniques, nonresponses, and data coding errors. The BRFSS, however, attempts to minimize such errors by using a large sample size and imposing quality assurance measures. Furthermore, although telephone surveys are easy to conduct and are cost-effective, they may have suboptimal response rates and may introduce noncoverage bias because they cannot include households without a telephone. The BRFSS, however, accounts for such variance by poststratification and weighting adjustments to the data. In addition, the term "personal health care provider" does not differentiate primary care physicians from non-primary care physicians or from mid-level providers. The authors stratified the response of having a PHP as "one," "more than one," and "no" to identify a more traditional primary care relationship (ie, having one PHP). Another consideration is that "more than one" responders may indicate 2 primary care clinicians, either working in the same clinic or one being a specialist, especially among older respondents. Although the authors do not feel this factor impacts the study's overall findings or conclusions, it is worth noting.

Our study attempted to mirror the US Preventive Services Task Force guidelines for cervical and breast cancer screening. ${ }^{20,21}$ The US Preventive Services Task Force modified the guidelines for cervical cancer screening (starting age changed from $\geq 18$ years to $\geq 21$ years) in 2003 , the current study followed the 2003 guidelines. In addition, as discussed earlier, BRFSS questions did not ask about the purpose of having a mammogram (screening vs diagnostic). It would be prudent for future studies to assess the difference in mammogram screening and diagnostic testing. Finally, the cross-sectional nature of the present study precludes any determination of causality.

The present study not only highlights the impact of having a PHP on adequate cancer screening, it also suggests that PHPs have a pivotal role in reforming US health care. The study findings are especially relevant in the light of the increasing trend among the US population to identify primary care as their "medical home" to address most of their medical problems, including preventive services utilization, such as cancer screening. ${ }^{22}$ With the dwindling number of medical students entering primary care, there is a great concern for the future health of populations, including cancer outcomes. More evidence about the health care workforce's impact on health care utilization and health care outcome is needed to make evidence-based decisions related to US health care reform.

\section{References}

1. Ginsburg JA, Doherty RB, Ralston JF Jr, et al. Achieving a high-performance health care system with universal access: what the United States can learn from other countries. Ann Intern Med 2008; 148:55-75.

2. Starfield B. Is US health really the best in the world? JAMA 2000;284:483-5.

3. Donaldson MS, Yordy KD, Lohr KN. Primary care-America's health in new era. Washington DC: National Academy Press; 1996.

4. Starfield B, Shi L, Macinko J. Contribution of primary care to health systems and health. Milbank Q 2005;83:457-502.

5. Nash D, Chan C, Horowitz D, Vlahov D. Barriers 
and missed opportunities in breast and cervical cancer screening among women aged 50 and over, New York City, 2002. J Womens Health (Larchmt) 2007; $16: 46-56$.

6. Hsia J, Kemper E, Kiefe C, et al. The importance of health insurance as a determinant of cancer screening: evidence from the Women's Health Initiative. Prev Med 2000;31:261-70.

7. Coughlin SS, Leadbetter S, Richards T, Sabatino SA. Contextual analysis of breast and cervical cancer screening and factors associated with health care access among United States women, 2002. Soc Sci Med 2008;66:260-75.

8. US Department of Health and Human Services, Agency for Healthcare Research and Quality. National Healthcare Disparities Report, 2005. Available at: http://www.ahrq.gov/qual/Nhdr05/nhdr05.htm. Accessed 18 October 2009.

9. National Cancer Institute. Surveillance Epidemiology and End Results Cancer Statistics Review, 19752006. Available at: http://seer.cancer.gov/csr/1975_ 2006/index.html. Accessed 4 May 2009.

10. Gill JM, McClellan SA. The impact of referral to a primary physician on cervical cancer screening. Am J Public Health 2001;91:451-4.

11. Selvin E, Brett KM. Breast and cervical cancer screening: sociodemographic predictors among white, black, and Hispanic women. Am J Public Health 2003;93:618-23.

12. Centers for Disease Control and Prevention. Behavioral Risk Factor Surveillance System annual survey data. Available at: http://www.cdc.gov/BRfss/technical_ infodata/weighting.htm. Accessed 4 May 2009.

13. Lurie N, Margolis KL, McGovern PG, Mink PJ, Slater JS. Why do patients of female physicians have higher rates of breast and cervical cancer screening? J Gen Intern Med 1997;12:34-43.

14. Zapka JG, Puleo E, Taplin S, et al. Breast and cervical cancer screening: clinicians' views on health plan guidelines and implementation efforts. J Natl Cancer Inst Monogr 2005;(35):46-54.

15. Hewitt M, Devesa SS, Breen N. Cervical cancer screening among US women: analyses of the 2000 National Health Interview Survey. Prev Med 2004; 39:270-8.

16. Bessler P, Aung M, Jolly P. Factors affecting uptake of cervical cancer screening among clinic attendees in Trelawny, Jamaica. Cancer Control 2007;14:396404.

17. Coughlin SS, King J, Richards TB, Ekwueme DU. Cervical cancer screening among women in metropolitan areas of the United States by individual-level and area-based measures of socioeconomic status, 2000 to 2002. Cancer Epidemiol Biomarkers Prev 2006;15:2154-9.

18. Jerant AF, Franks P, Jackson JE, Doescher MP. Age-related disparities in cancer screening: analysis of 2001 Behavioral Risk Factor Surveillance System data. Ann Fam Med 2004;2:481-7.

19. Facione NC. Breast cancer screening in relation to access to health services. Oncol Nurs Forum 1999; 26:689-96.

20. US Department of Health \& Human Services, Agency for Healthcare Quality and Research, US Preventive Services Task Force. Screening for cervical cancer: recommendations and rationale. Available at: http://www.ahrq.gov/clinic/3rduspstf/cervcan/ cervcanrr.htm. Accessed 4 May 2009.

21. US Department of Health \& Human Services, Agency for Healthcare Quality and Research, US Preventive Services Task Force. Screening for breast cancer: recommendations and rationale. Available at: http://www.ahrq.gov/clinic/3rduspstf/breastcancer/ brcanrr.htm. Accessed 4 May 2009.

22. Grumbach K, Bodenheimer T. A primary care home for Americans: putting the house in order. JAMA 2002;288:889-93. 